University of Nebraska - Lincoln

DigitalCommons@University of Nebraska - Lincoln

2016

Monitoring, Measuring, and Modeling a Reservoir Flush on the Niobrara River in the Sandhills of Nebraska

Stanford Gibson

Paul Boyd

Follow this and additional works at: https://digitalcommons.unl.edu/usarmyceomaha

This Article is brought to you for free and open access by the U.S. Department of Defense at

DigitalCommons@University of Nebraska - Lincoln. It has been accepted for inclusion in US Army Corps of Engineers by an authorized administrator of DigitalCommons@University of Nebraska - Lincoln. 


\title{
Monitoring, Measuring, and Modeling a Reservoir Flush on the Niobrara River in the Sandhills of Nebraska
}

\author{
Stanford Gibson, $\mathrm{PhD}$ \\ US Army Corps of Engineers, Hydrologic Engineering Center, Davis, California, USA \\ Paul Boyd, PhD, PE \\ US Army Corps of Engineers, Omaha District, Omaha, Nebraska, USA
}

\begin{abstract}
Organizations managing aging dams and those designing new dams must consider the long term sediment sustainability of these projects. Flushing, a common sustainable management alternative, entrains and transports reservoir delta deposits by drawing the reservoir down to run of river flows. Agencies often apply one-dimensional sediment transport models to design these flush releases and predict their impact. A flushing event at Spencer Dam on the Niobrara River was monitored, measured, and modeled with HEC-RAS 5.0, an unsteady, one-dimensional (1D), mobile bed sediment model. This paper documents qualitative observations from the flush and compares model results to prototype measurements to evaluate the viability of 1D assumptions for flushing analyses. Reservoir stratigraphy, including cohesive layers deposited during large flows, decreased flushing efficiency. The model performed well in upper half of the reservoir where the model computed scour within $4 \%$ of measured erosion, with almost no parameter adjustment. The model also predicted deposition downstream of the dam well, within $5 \%$ of observed values. The model under-predicted erosion in by $43 \%$ in lower half of the reservoir, missing sediment eroded by lateral mechanics (e.g. toe scour, undercutting, and bank failure). Reservoir stratigraphy (e.g. clay lenses deposited during large events) affected the pattern of channel formation and total sediment removal. Finally, the model reproduced the timing and magni-
\end{abstract}

\section{INTRODUCTION}

Sediment deposition decreases the storage capacity of reservoirs over their design life, eventually impacting operational objectives (Morris and Fan, 1997). Many agencies managing aging reservoir infrastructure are already dealing with sediment impacts to reservoir functions and benefits, often without infrastructure designed to manage long term sediment deposition. Those agencies building new dams around the world are also considering reservoir sediment sustainability measures. Carefully planning and integrating sustainable sediment management into new dam design could avoid difficult and expensive decisions those managing aging dams are facing, with strategic front end investment (Morris et al, 2008).

HEC-RAS 5.0 includes new sediment features designed to improve sustainable reservoir sediment management analysis (Gibson and Boyd, 2015). These tools have been applied to several sustainable sediment studies but, because reservoir flushing is rare in the United States, they have not been validated against an actual sediment flushing event.

Spencer Dam on the Niobrara River is one of the only reservoirs in the United States which consistently operates for sediment sustainability objectives. This reservoir flushes sediment twice a year, opening a sluice gate 6 to $7 \mathrm{~m}$ below operational reservoir stage for at least two weeks during each flush. Operators skipped the flush in the spring of 2014, leaving one full year of accumulation in the reservoir for the fall 2014 flush. A year of deposition nearly filled this reservoir, providing an opportunity to measure and model a substantial flushing event in a well-developed reservoir delta. The predictable and substantial flushing events at Spencer Dam made it an ideal laboratory to measure sediment responses to a reservoir flush and test the 1D sediment transport assumptions in HEC-RAS against prototype data.

The US Army Corps of Engineers (USACE) surveyed repeated cross sections before and after the flush to measure the volume change upstream, within, and downstream of the reservoir. The US Geological Survey (USGS) measured sediment concentrations upstream and at three stations downstream of the dam every few hours during the initial flush and then less frequently over the course of the four week draw down. The team also examined and cored the postflush deposits, making quantitative and qualitative observations about the reservoir stratigraphy and transport dynamics.

The need to accurately model a drawdown flush in a sand delta reservoir is driven by the Lewis and Clark Lake Sediment Management Study, a science unit of 
the Missouri River Recovery Program, (LCLSMS 2013) which evaluates sediment management processes both above and below Gavins Point dam for endangered species habitat and reservoir longevity. Extensive GSTARS4 and HEC-RAS modeling has been completed on flushing scenarios on Lewis and Clark Lake. However, since Lewis and Clark reservoir has never been flushed these models cannot be validated. Modeling the Spencer Dam flush tested the 1D assumptions on a smaller scale reservoir, to decrease the uncertainty of the Lewis and Clark models.

The Spencer flush was modeled in HEC-RAS and results compared to repeated cross section and downstream concentration data to evaluate 1D sediment transport model assumptions.

\section{SETTING AND FLUSH DESCRIPTION}

The precursor to the Nebraska Public Power District (NPPD) built Spencer Dam on the Niobrara River (Figure 1) in north central Nebraska, $64 \mathrm{~km}$ upstream of the confluence with the Missouri River, where it is the primary sediment load to Lewis and Clark Lake behind Gavins Point Dam. The Niobrara River drains the sand hills west of the Missouri River. The dam is a 9.1 meter high concrete buttress-type structure with two hydroelectric turbines that generate a total of 3.3 megawatts (nameplate). The dam has four tainter gates and one ice sluice gate (Hotchkiss and Huang 1994)

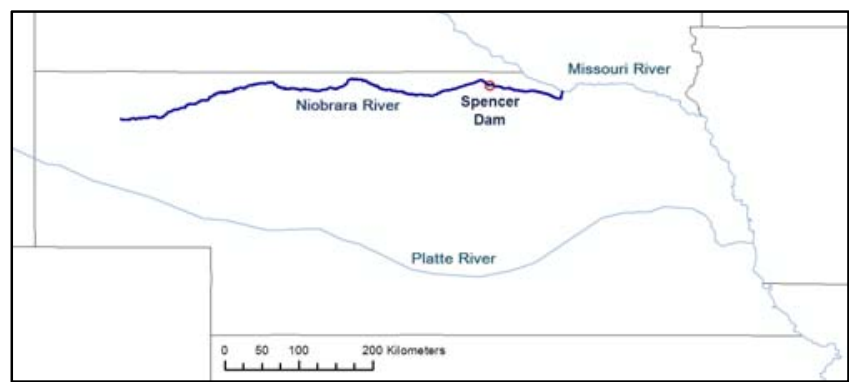

Figure 1: Location of Spencer Dam on the Niobrara River, a tributary of the Missouri River.

Spencer dam captures flow and sediment from most of the Niobrara watershed. The initial capacity of the reservoir in 1925 was $12.9 \times 10^{6} \mathrm{~m}^{3}$ and the reservoir area was 485 hectares. The U.S. Army Corps of Engineers (USACE) conducted a survey of the reservoir in October 1949. They found that sediment deposition had reduced reservoir capacity to 43,000 $\mathrm{m}^{3}$ (Mares, 1991). In the 1950's, NPPD retrofitted it with sluicing gates to manage the sediment. Since then, operators have opened the sluice gates twice a year, drawing the reservoir down to run of river conditions for roughly two weeks at a time.
NPPD skipped the Spring 2014 flush. The sediment that deposited between the October 2013 and October 2014 flushes nearly filled the reservoir. Therefore NPPD the reservoir for four weeks in October 2014, to evacuate a full year of deposition. Spencer dam operators opened two gates after midnight, the morning of October 6, 2014, slowly drawing the reservoir down less than a meter overnight to minimize fish stranding. This increased the pre-flush release concentration above background but concentrations during this period were minor compared to the flush. At 08:00 on October 6, Spencer dam operators opened the four main gates (Figure 2), increasing the gate openings each hour until about 13:20 when they opened the sluice gate, a fifth gate with an invert elevation 1.5 meters lower than the others. Opening the main gates increased release concentrations dramatically, but the sluice gate pushed a head cut rapidly upstream through the reservoir sediment. The flush continued with run of river flow until NPPD closed the gates on November 7, 2014.

\section{MONITORING DATA}

The study team collected three measurements to quantify the flush response: 1) repeated cross sections before and after the four week flush, 2) sediment concentrations downstream of the flush, and 3) reservoir sediment gradations.

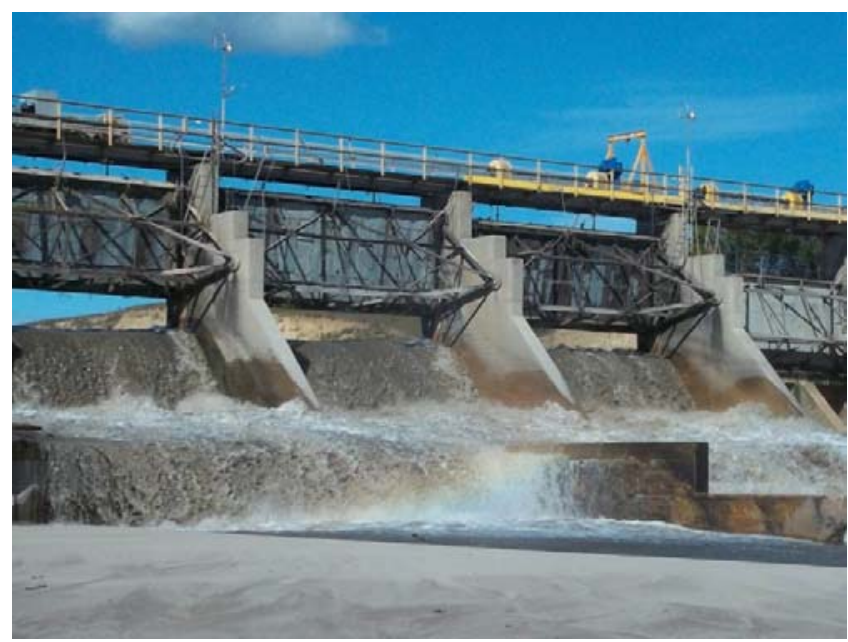

Figure 2: Sediment laden water flowing over the main gates early in the Spencer Dam flush.

USACE measured cross sections before and after the flush. They collected 26 cross sections in reservoir and within the first kilometer downstream of the dam, for an average cross section spacing of $75 \mathrm{~m}$. They re-surveyed the cross sections immediately after the flush.

Unseasonably cold weather froze the reservoir on the same day that NPPD refilled it. This development 
complicated the post flush survey. To compute bed change the modeling team inferred geometry change in select locations where the post-flush survey was incomplete. USACE surveyors returned to collect cross sections before and after the spring 2015 flush, which generated similar cross section shapes where they overlapped. The Spring 2015 cross sections helped infer elevations missing from the Fall 2014 survey.

The US Geological Survey collected depth integrated, suspended sediment samples downstream of the flush, at three stations, $1 \mathrm{~km}, 19 \mathrm{~km}$, and $40 \mathrm{~km}$ downstream. The sampling station $1 \mathrm{~km}$ downstream of the dam had the finest temporal resolution, including 47 samples at 24 sample times (most samples included one replicate seven minutes later). Over half of these samples (29 samples at 15 times) were collected in the first three days of the flush. Another 12 samples (6 times) were spread over the next three days (October 9-11, 2014) and the rest were collected either before the flush or weekly, during the four weeks the reservoir was drawn down.

Finally, the USACE collected 17 surficial sediment gradations along one kilometer of the sediment delta before the flush. These samples were very uniform. Most samples included over $90 \%$ fine and medium sand (0.125-0.5 mm), with some silty sand at the forest slope of the delta.

\section{MORPHOLOGICAL OBSERVATIONS}

In four weeks, the fall 2014 flush eroded just under $700,000 \mathrm{~m}^{3}$ of reservoir sediment, depositing approximately $100,000 \mathrm{~m}^{3}$ of that in the 500 m reach directly downstream of the dam. The drawdown did not erode sediment uniformly, favoring historic channels and stranding large mud flats where the flow encountered thick clay layers which did not erode before the main channel incised and dropped the water level too far to erode them.

Morphological evolution followed the classic channel evolution model (Schumm et al. 1984). The drawdown pushed a head cut upstream through the reservoir deposits (Figure 3 - top), incising two relatively confined channels in the first few hours.

After the initial head cut lateral erosion (e.g. toe scour and slumping) rapidly widened the channels, more than doubling their width over the next 10 hours (Figure 3 - middle). Meanwhile, the channels continued to incise. One of the head cut channels - a historic channel along the right bank, discernable in the pre-flush cross sections - captured the flow overnight. It incised within the first 20 hours of the flush, stranding the mid-delta channel (Figure 3 - bottom). Visual inspection on subsequent visits suggests that channel continued to erode and expand during the four week flush, but the channel form did not change significantly after the first 24 hours.
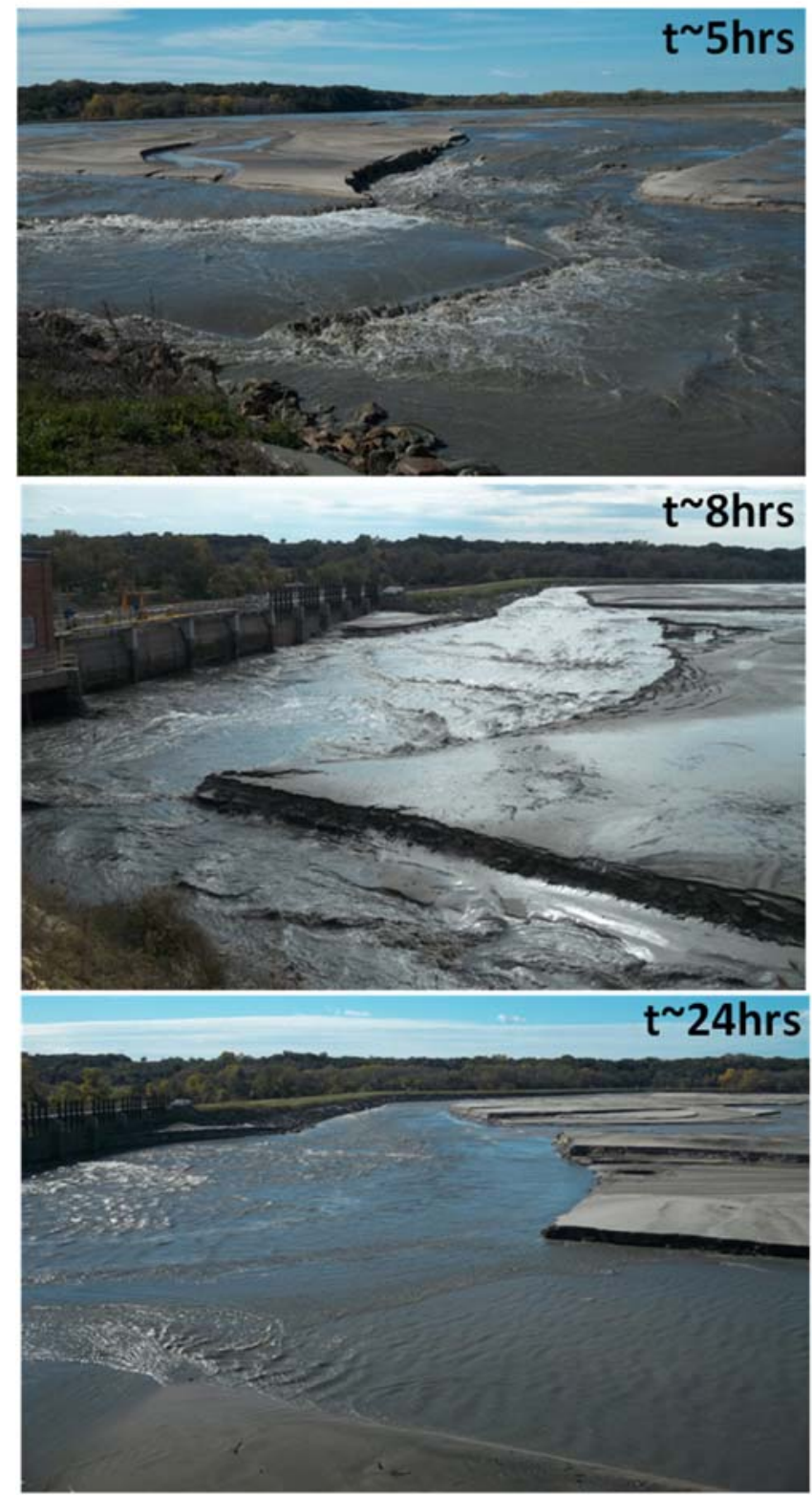

Figure 3. Evolution of the Spencer Reservoir sediment delta during the flush. The head cut propagated upstream shortly after the flushing gate was opened (top). Then the channel deepened and widened the rest of the first day (middle), until it settled into a form close to the final geometry 24 hours after the flush (bottom).

USACE samplers inspected the reservoir deposits 24 hours after the flush. They collected sediment cores and recorded stratigraphy of freshly developed vertical banks, cut by incising and stranded channels. These samples and stratigraphic cross sections were much more complex than the Fine to Medium Sand Surface samples collected before the flush. They included thick clay lenses (Figure 4) and even occasional fine gravel deposits lodged in distinct cross bedding features (Figure 5). Clay lenses also appeared 
as large ( $>1$ ha) surficial mud flats, where the flushing flows removed sand deposits until it exposed the cohesive material. Erosion presumably slowed once the flow encountered the less erodible cohesive material, and channel incision stranded the mud flat before flushing flows could scour through it.

The bottom of several of these clay layers were lined with debris (e.g. hay, sticks, and other large organic material), suggesting these fine layers correspond to flood events. This corroborates Colby and Hembree (1955) (cited in Walling and Moorhead, 1989) who reported that the Niobrara load fines with flow, transporting primarily cohesive material, during large events (when load exceeds 5,000 tons/day).

After the flush a broad taxonomy of bed forms covered the exposed, surficial, reservoir sediment (including wavelengths from approximately 10 to $30 \mathrm{~cm}$ and with amplitudes mostly less than $15 \mathrm{~cm}$ ). Two novel bed forms were observed. First "topographic bed forms," (Figure 6) occurred in exposed sand deposits in the upstream half of the delta. These bed forms included several horizontal ridges, resembling a three-dimensional topographic map. These ridges probably eroded into the features as the water surface dropped in discrete increments due to a non-linear downstream control.

Second, the high energy environment induced by the flush transported clay in "rollers" (Figure 7) These were observed during the flush, where they looked like cobbles rolling along the top of transporting sand. The flush eroded sand under the clay lenses, caving chunks of these lenses into the high energy flow field. The flow transported these clods, eventually forming them into cylindrical, cobble size casts (usually about $10 \mathrm{~cm}$ long, but up to approximately $30 \mathrm{~cm}$ ) that transported through the flush gates.

Antidunes were also observed in several temporary, high energy environments as the delta morphology adjusted over the first 48 hours. Antidunes were usually observed in shallow water, upstream of a flow constriction, and were always periodic. Standing waves formed upstream of constrictions, and move one to two meters upstream for one to two minutes. Then they washed out and within a minute, started again.

Repeated cross sections were collected before and after the Spring 2015 flush. These measurements and visual reconnaissance demonstrated that the Spring 2015 flush converged to a similar morphology as the Fall 2014 event. However, while the Fall 2015 flush was not measured, it clearly diverged from the previous events. Instead of concentrating most of the flow in a channel along the right bank, like the previous two events, the Fall 2015 flush cut a new channel through the center of the delta, through deposits the previous flushes stranded.

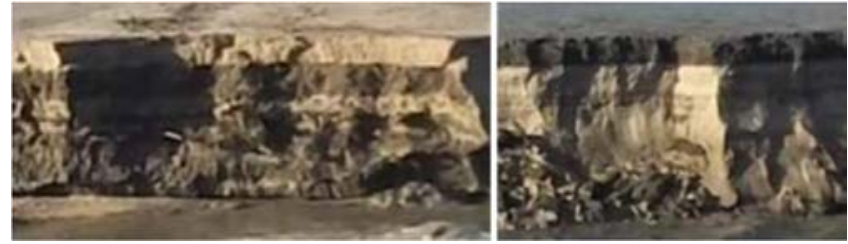

Figure 4. Clay lens (left) and clay lens exposed as mud flat (right)

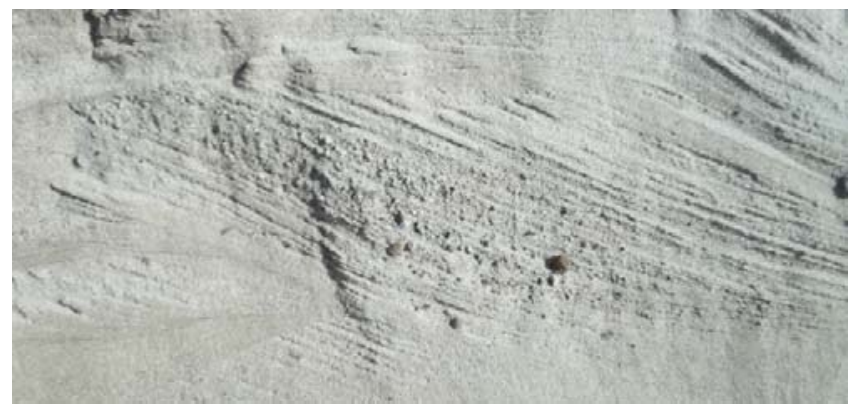

Figure 5. Fine gravel embedded in cross bed sand deposits.

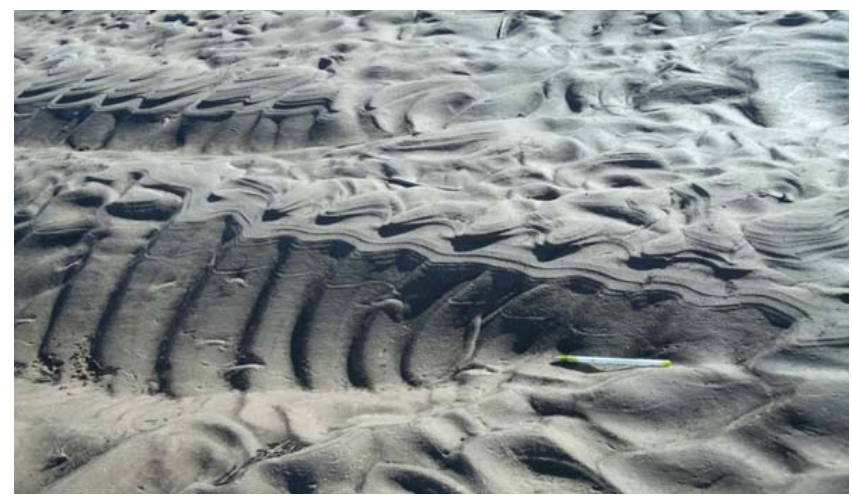

Figure 6. Topographic dune.

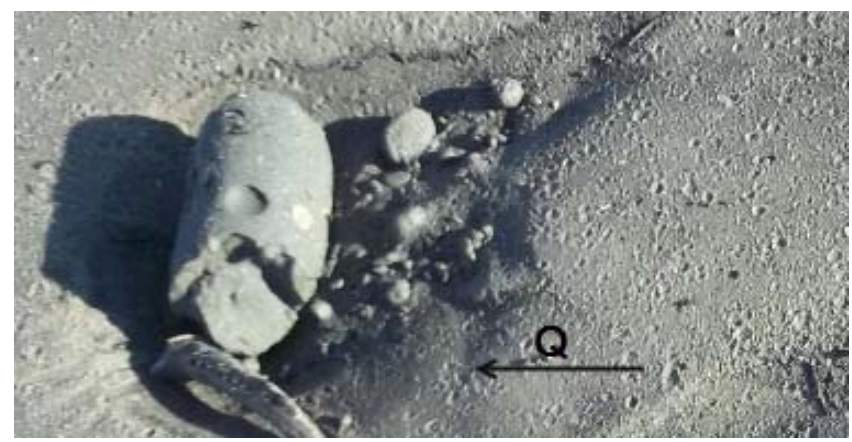

Figure 7. Clay roller, a chunk of a clay lens, undermined and sloughed into the flow field, transported into a cylindrical rolling clast (about $10 \mathrm{~cm}$ long). 


\section{HEC-RAS FLUSHING MODEL}

An HEC-RAS 5.0 unsteady sediment model (Gibson and Boyd, 2015) was developed to model this event and to evaluate the flushing algorithms and the $1 \mathrm{D}$ assumptions against prototype data. The model was constructed with the October 2014 pre-flush cross sections. The HEC-RAS cross section layout is mapped with the georeferenced survey points in Figure 8. The dam was modeled with an inline structure. Gate operations were translated into gate time series.

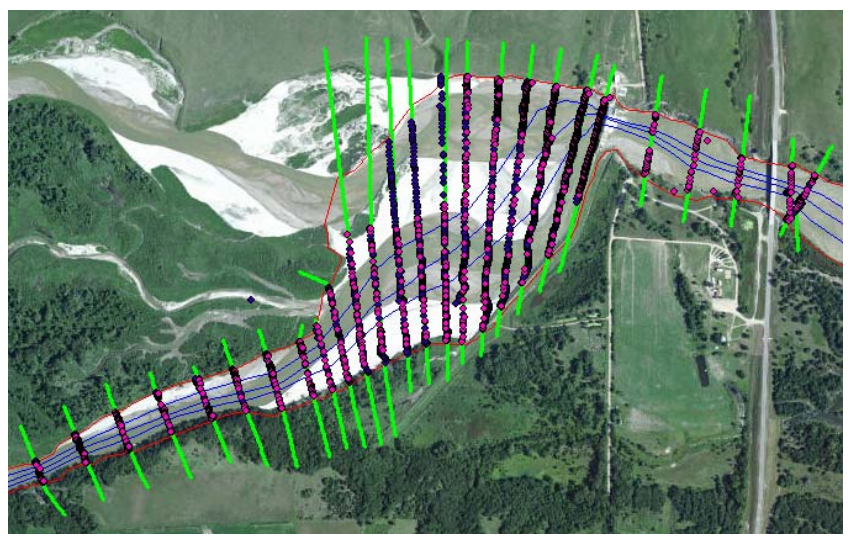

Figure 8. Surveyed cross sections and HEC-RAS model cross sections superimposed on an aerial photograph of Spencer Reservoir.

Unsteady sediment transport capabilities in HECRAS 5.0 integrate a classic continuity sediment routing approach with its implicit Saint-Venant hydrodynamic solution. HEC-RAS 5.0 solves the Exner equation over control volumes centered on each cross section based on the hydraulic parameters computed for each unsteady flow time step.

The final model used the Yang (1976) sediment transport function. The incision rate was sensitive to the transport function selected, but total sediment eroded during the flush was not. Bed mixing was modeled with the Copeland (1993) algorithm, designed to simulate erosion on large sand bed rivers. However, results were not highly sensitive to mixing method selected either.

Unsteady flow simulations in HEC-RAS compute the entire time series with a single time step. Drawdown conditions introduced steep friction slopes, translating to very high shear stresses. At coarse time steps these shear conditions made the bed unstable, over-predicting erosion during time steps as the flush gate opened, and introducing bed and hydraulic instabilities. At six second time steps, the model ran without instabilities. Additionally, the sluice gate in the model was opened more slowly than the prototype to improve model stability.

Bed gradations were defined based on surface samples collected before the flush. Model results were insensitive to sediment boundary conditions since transport, concentrations, and bed change were driven by local, high energy conditions and stored sediment rather than boundary fluxes during the flush. Therefore, a simple equilibrium load boundary was defined at the upstream cross section. The model was run with low and high boundary loads to demonstrate insensitivity to this parameter.

\section{MODEL RESULTS}

Model results were evaluated against two field metrics: 1) reservoir sediment volume change and 2) downstream suspended sediment concentration.

\subsection{Bed Volume Change}

The measured and computed longitudinal cumulative volume change (the sum of volume change from upstream to downstream within the model reach) is plotted in Figure 9. The flush scoured the reservoir delta sediments and the channel upstream of the reservoir, eroding much more sediment from the delta. It deposited about 1/7th of the sediment it scoured from the reservoir, immediately, forming a massive right channel bar in the $500 \mathrm{~m}$ downstream of the dam.

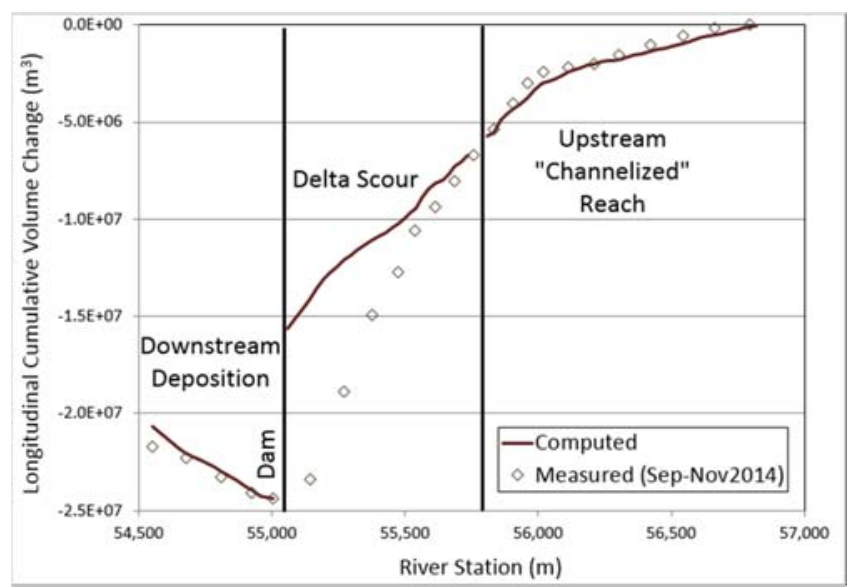

Figure 9. Measured longitudinal cumulative bed change between the pre- and post- flush cross section plotted with HECRAS volume results, subdivided into three regions.

The model performed very well upstream and downstream of the reservoir delta. HEC-RAS computed total reach volume change within $4 \%$ of the measured erosion in the upper half of the reservoir, where there was an established channel. The model also predicted total reach deposition within $5 \%$ of the measurements in the $500 \mathrm{~m}$ downstream of the dam. In the reservoir delta, the $1 \mathrm{D}$ model under-predicted scour by approximately $43 \%$.

Final measured and computed cross sections are plotted with the initial, pre-flush survey from a mid- 
delta cross section in Figure 10. These results demonstrate the strength and limitation of the model. The model predicted incision depth very well, but the 1D assumptions did not capture the second morphological stage, where the flushing flow undercut the mud flats and eroded the bank laterally. This lateral scour phase was an important process in the delta (Figure 11). Resistant layers may have made lateral processes more important, since they maintained vertical channel banks until toe scour undermined sand layers below them, causing slumping or cantilever failures.

This, however, is not a strictly 1D limitation. Most sediment models are limited to eroding wet nodes. Unless models include algorithms to undermine dry nodes, or expand the channel, models will miss the second two stage of these rapidly developing channels, since the incision stage strands them, leaving them dry and impervious to bed change regardless of model dimensionality. To simulate these effects, $1 \mathrm{D}$ or multi-dimensional morphology models must be coupled with some geotechnical or lateral process model (e.g. Gibson et al, 2015).

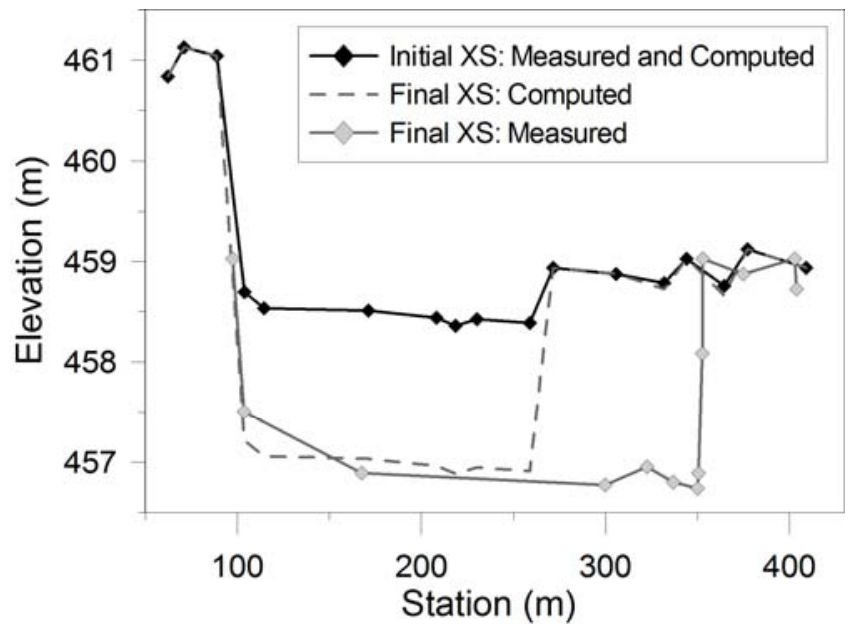

Figure 10: Measured and computed cross sections before and after the flush at a representative, mid-delta transect.

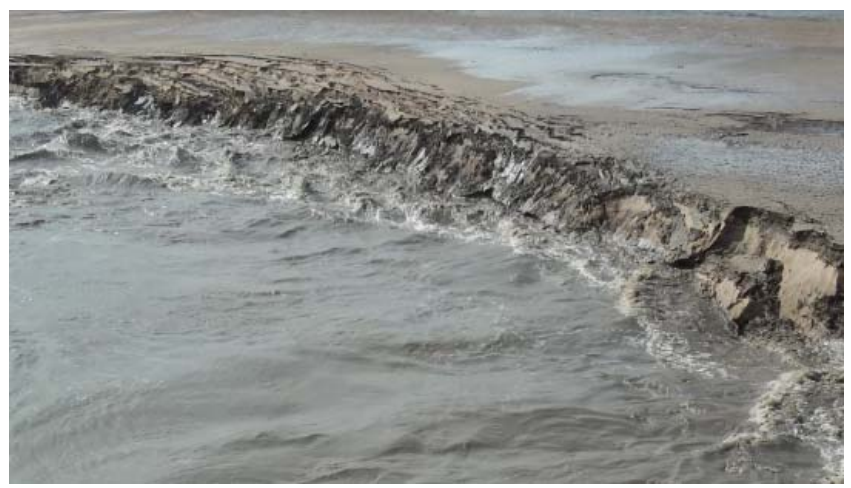

Figure 11. Lateral channel expansion, through toe scour, undercutting clay lenses, and sloughing moved a substantial amount of reservoir sediment during the first twenty four hours of the flush.
Bed change results were relatively insensitive to algorithm (e.g. transport function or mixing approach), initial conditions (e.g. bed gradation), or parameterization (e.g. critical shear). Adjusting model assumptions or data affected the bed change rate more than the final result.

\subsection{Concentration}

Model results were also compared to the suspended sediment concentrations the USGS measured $500 \mathrm{~m}$ downstream of the dam. The observed and computed concentrations are plotted in Figure 12. HEC-RAS reports total load concentration while the measured concentrations only include suspended load. Therefore computed results should plot along the upper bound of observations. The model reproduced the magnitude and the timing of the measured concentration time series reasonably well.

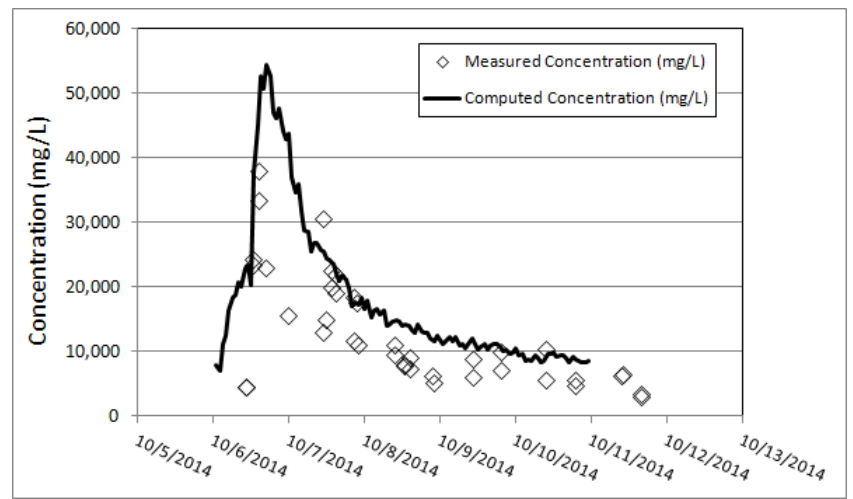

Figure 12. Concentration measured $500 \mathrm{~m}$ downstream of the dam during the flush and the concentration computed at that location by HEC-RAS.

While the model predicted most of the reservoir scour during the first four days of the flush, it computed non-trivial sediment transport in the following weeks. $40 \%$ of the total sediment the model eroded from the reservoir transported after the first four days of the flush, mostly from the reach upstream of the delta. This result was surprising, but was corroborated by qualitative and quantitative field evidence. While the channel form did not change appreciably after the first 24 hours, the extents did. Intermediate cross sections were not measured, but enough sediment eroded between the fourth day and the end of the fourth week that channel change could be detected visually. Additionally, the suspended sediment concentrations measured in the later three weeks of the flush were elevated above background (Table 1). 
Table 1. Concentration measurements $500 \mathrm{~m}$ downstream of the dam after three and four weeks of the flush, compared to background concentrations one week before and four days after the flush.

\begin{tabular}{lcc}
\hline $\begin{array}{l}\text { Measurement } \\
\text { Date }\end{array}$ & $\begin{array}{c}\text { Time Relative } \\
\text { To Flush Start }\end{array}$ & $\begin{array}{c}\text { Concentration } \\
\text { Range (mg/L) }\end{array}$ \\
\hline Oct 2, 2014 & $\begin{array}{c}\text { Background: } \\
\text { Before Flush }\end{array}$ & $67-72$ \\
\hline Oct 21, 2014 & $\begin{array}{c}\text { 3 Weeks After Start } \\
\text { Last Day of Flush }\end{array}$ & 2050-2130 \\
\hline Nov 7, 2014 & $\begin{array}{c}\text { 4 Weeks After Start } \\
\text { Last Day of Flush }\end{array}$ & $1620-1950$ \\
\hline Nov 11, 2014 & $\begin{array}{c}\text { Background: } \\
\text { After Flush }\end{array}$ & 228-298 \\
\hline
\end{tabular}

\section{CONCLUSIONS AND FUTURE WORK}

Reservoir stratigraphy (e.g. clay layers deposited during flood events) can affect flushing, decreasing overall erosion.

An HEC-RAS model simulated the reservoir results relatively well. The model was particularly accurate upstream and downstream of the main reservoir delta, where it reproduced flushing erosion and deposition within $5 \%$ of observed bed change and was relatively insensitive to user selected parameters. HEC-RAS also reproduced the concentration time series downstream of the dam reasonably well. The model under predicted scour in the main reservoir delta, missing the lateral processes important in the second stage of channel evolution.

The 1D model performed reasonably well predicting a reservoir flushing response in a sand river reservoir delta. It would be useful to test these assumptions in other conditions. Future work involves coupling the 1D incision model with the toe scour and bank erosion model in HEC-RAS (the ARS-USDA Bank-Stability and Toe Erosion Model (BSTEM)) (Gibson et al., 2014) to account for the lateral processes and improve model performance in the reservoir delta.

\section{ACKNOWLEGEMENTS}

This work was funded primarily by the US Army Corps of Engineers Regional Sediment Management Research Program. The suspended sediment samples were funded by the USGS Large Rivers Initiative and the Missouri River Recovery Program. The sampling team from the USGS Nebraska Water Science Center collected the suspended sediment data and provided helpful experimental design guidance. The Omaha District USACE River and Reservoir Engineering section provided the resources for additional reservoir surveys in the spring of 2015. Unsteady sediment transport and sediment flushing capabilities in HECRAS 5.0 were funded by Corps of Engineers Flood and Coastal Storm Damage Reduction R\&D Program. NPPD provided reservoir access, historical context, gate and gage data, detailed explanations, and helpful insights, making this work possible.

\section{REFERENCES}

Colby, B.R., Hembree, C.H., 1955. Computations of total sediment discharge Niobrara River, near Cody, Nebraska. US Geological Survey Water Supply Paper 1357.

Copeland, R 1993. Numerical Modeling of Hydraulic Sorting and Armoring in Alluvial Rivers. PhD Thesis, The University of Iowa.

Gibson, S. and Boyd, P. 2014. Modeling Long Term Alternatives for Sustainable Sediment Management Using Operational Sediment Transport Rules. in Scheiss et al. (eds) Reservoir Sedimentation, 229236.

Gibson, S., Simon, A., Langendoen, E., Bankhead, N., and Shelley, J. 2015. A Physically-Based Channel-Modeling Framework Integrating HEC-RAS Sediment Transport Capabilities and the USDA-ARS Bank-Stability and Toe-Erosion Model (BSTEM). Federal Interagency Sediment Conference, SedHyd Proceedings.

Hotchkiss, R.S. and Huang, X. 1994. Preliminary Hydrosuction Sediment Removal System Design for Spencer Reservoir. Project Report Number HRS-001, Dept. of Civil Engineering, University of Nebraska at Lincoln.

Mares, D.E. 1991. Feasibility of Meodleing Regional Reservoir Sedimentation: Numerical Approach. Master's Thesis, University of Nebraska at Lincoln.

Morris, G.L, Annandale, G., Hotchkiss, R. 1008. Reservoir Sedimentation. ASCE 110, Sedimentation Engineering 12:579-612.

Morris, G.L. Fan J. 1997. Reservoir Sedimentation Handbook: Design and Management of Dams, Reservoir and Watersheds for Sustainable Use. McGraw-Hill, New York.

Boyd, P.M. and S. Gibson 2016. Applying 1D Sediment Models to Reservoir Flushing Studies: Measuring, Monitoring, and Modeling the Sepncer Dam Sediment Flush with HEC-RAS. Regional Seidment Management Program, ERDC/CHL CHETN-XXX$\mathrm{XX}$ (in press).

LCLSMS 2013. Lewis and Clark Lake Seidment Management Study: Phase II Fact Sheet May 2013. U.S. Army Corps of Engineers, Omaha District.

Schumm, S.A., M.D. Harvey, Watson, C.C., 1984. Incised Channels: Morphology, Dynamics, and Control. Water Resources Publications, Littleton, Colorado. 
Yang, C.T. 1972. Unit sream power and sediment transport. Journal of Hydraulics Division, American Society of Civil Engineers, 98(HY10):1805-1826.

Walling, D.E., Moorehead, P.W. 1989. The particle size characteristics of fluvial suspended sediment: an overview. Developments in Hydrobiology, 50:125-149. 